\title{
Correlation Between Ocular Rigidity with Intraocular Pressure in Patient with Type 2
}

\section{Diabetes Mellitus}

Roland Iqbal $^{1 *}$, Prima Maya Sari ${ }^{1 *}$, Ramzi Amin $^{1 *}$, Fidalia $^{1 *}$

${ }^{1}$ Department of Ophthalmology, Faculty of Medicine, Universitas Sriwijaya, Indonesia

*Correspondence author email : rolandiqbal@gmail.com

\begin{abstract}
Introduction: Diabetes mellitus (DM) is known to have a biomechanical effect on tissue. High blood glucose concentrations that lead to increased production of free radical intermediates causes ocular rigidity (OR) changes. This change can effect intraocular pressure (IOP) in patients with type $2 \mathrm{DM}$. This study to determine correlation between ocular rigidity with IOP in patients with type $2 \mathrm{DM}$.

Methods: A cross-sectional study with a correlation test design of OR with IOP in type 2 DM patients was conducted in RSUP dr. Mohammad Hoesin Palembang from January until June 2018. Eighty eye samples consist of 60 type 2 DM and 20 control group. IOP examination was performed using a Goldmann applanation tonometer and OR measurements using schiotz tonometer with two loads then assessed in Friedenwald differential tables.

Result: There was a significant correlation between diabetic retinopathy and OR $(p=0,000)$. There was a significant correlation between OR and IOP in NPDR and PDR group $(\mathrm{p}=0,000)$. There was a significant relationship between patient age with OR and IOP $(\mathrm{p}<0,05)$.
\end{abstract}

Conclusion: There is a significant correlation between ocular rigidity and IOP in people with type $2 \mathrm{DM}$.

Keywords: Ocular Rigidity, Intraocular Pressure, Type 2 Diabetes Mellitus, Diabetic Retinopathy. 


\section{Introduction}

Diabetes mellitus is increasing at an alarming rate. In 1997, 124 million people worldwide had diabetes, with $97 \%$ of them having type 2 diabetes. By the year 2012, the total number of people with diabetes was more than 371 million. The development of diabetic complications is a major cause of morbidity and mortality and is an ever increasing burden to health care authorities in both developed and developing nations. Diabetic retinopathy, one of the major diabetic complications, may lead to visual disability and blindness. ${ }^{1}$

Diabetes mellitus is characterized high blood glucose concentrations that lead to increased production of free radical intermediates. The resulting glycative, glycoxidative, carbonyl and oxidative stress play a key role in pathogenesis of diabetes. Glycation is considered the cause of many of the damaging late complications. Initially, glycation affects the interactions of collagen with cells and other matrix components but the most damaging effects are caused by the formation of glucose-mediated intermolecular cross links. These cross-links decrease the critical flexibility and permeability of the tissues and reduce turnover. ${ }^{1}$

Ocular rigidity (OR) is a macroscopic parameter characterizing the relationship between pressure and volume changes in the human eye. Ocular rigidity depends on the architecture and material properties of the globe. Measurements of ocular rigidity have been mainly performed by means of invasive manometric devices or paired Schiotz tonometry. Moreover, rigidity has been shown to be altered in patients with age-related macular degeneration and glaucoma. In friedenwald's studies, ocular rigidity was found to be altered in uveitis patients. Patients with alterations in biomechanical properties of the cornea, such as keratoconus or osteogenesis imperfecta, exhibit lower ocular rigidity coefficient compared with normal controls; corneal thinning was found to correlate with ocular rigidity in these patients. So far, little is known about the possible relationship between ocular rigidity and diabetic retinopathy. Outflow facility is a measure of the resistance of the conventional outflow pathway of the aqueous humor. A former study has shown that outflow facility coefficient is low in diabetic patients compared to normal population.1,2

Althought it is well known that diabetes mellitus interferes with the vascular integrity of the ocular tissues, the relationship between diabetes and ocular rigidity has received little attention. The purpose of the present study is to investigate OR in diabetic patients compared to normal controls and evaluate a possible correlation of OR with the severity of diabetic retinopathy. 


\section{Methods}

A cross-sectional study with a correlation test design was conducted. It included 60 eyes diagnosed type 2 DM without or with DM retinopathy and 20 control group who attended Mohammad Hoesin Hospital between January until June 2018. One eye per patient was included in the study. Written informed consent was taken from all patients for the procedure. Information was collected on age, sex, involving eye, duration of diabetes (years), and gradation of DR.

Inclusion criteria were patients with type $2 \mathrm{DM}$ who had without retinopathy, NPDR and PDR, normal intraocular pressure $(<20 \mathrm{mmHg})$ and age $\geq 40$ years old. Exclusion criteria for both diabetic patients and controls were the presence anterior-posterior segment abnormality and ophthalmic disease other than diabetic retinopathy, history of previous intraocular surgery, laser treatment or intravitreal injection, glaucoma or ocular trauma and severe cardiovascular or pulmonary disease. Moreover, patients with connective tissue disorder, hereditary or autoimmune, were excluded from the study.

All patients underwent a thorough ophthalmic assessment including visual acuity, slit lamp biomicroscopy and Goldmann applanation tonometry. The diagnosis of diabetic retinopathy was based on the appearance of the retina on dilated fundus examination and classified according to the Early Treatment.

Diabetic Retinopathy Study Classification. Axial length measurements was performed with ultrasonic biometry. Ocular rigidity measurements using schiotz tonometer with two loads, 5,5 and 10 grams, then assessed in Friedenwald differential tables. We performed statistical analyses using SPSS version 20 statistical software. The null hypothesis was rejected for $P$-values $<0,05$.

\section{Results}

A total of eighty eye samples consist of 60 diabetic patients and 20 patients nondiabetic (control group) were enrolled. All included 44 female (55\%) and 36 male (45\%) eye samples with mean age was $48,14 \pm 4,09$ years (range 40 - 60). The characteristics of the subjects are described in table 1,2 and 3.

Table 1. Sociodemography Characteristics

\begin{tabular}{|l|c|c|c|}
\hline \multicolumn{1}{|c|}{ Sociodemography } & $\mathbf{N}$ & $\mathbf{\%}$ & Average \\
\hline Age & & & \\
\hline$\leq 50$ year & 58 & 72,5 & \\
\hline$>50$ year & 22 & 27,5 & $48,14 \pm 4,09$ \\
\hline
\end{tabular}




\begin{tabular}{|l|c|c|l|}
\hline \multicolumn{1}{|r|}{ Total } & 80 & 100 & \\
\hline Gender & & & \\
\hline Male & 36 & 45 & \\
\hline Female Total & 80 & 100 & \\
\hline & & & \\
\hline Education & 9 & 11,25 & \\
\hline Elementary school & 8 & 10 & \\
\hline Secondary school & 38 & 47,5 & \\
\hline Senior high school & 25 & 31,25 & \\
\hline Collage Total & 80 & 100 & \\
\hline \multicolumn{2}{r|}{} \\
\hline
\end{tabular}

Table 2. Clinical Characteristic

\begin{tabular}{|c|c|c|c|}
\hline Clinical & $\mathbf{N}$ & $\%$ & Average \\
\hline \multicolumn{4}{|l|}{$\begin{array}{l}\text { Gradation } \\
\text { Diabetic } \\
\text { Retinopathy } \\
\end{array}$} \\
\hline Non DM & 20 & 25 & \\
\hline $\begin{array}{l}\text { DM } \\
\text { Without } \\
\text { Retinopathy }\end{array}$ & 20 & 25 & \\
\hline \multicolumn{4}{|l|}{ NPDR } \\
\hline Mild NPDR & 6 & 7,5 & \\
\hline Moderate NPDR & 7 & 8,75 & \\
\hline Severe NPDR & 7 & 8,75 & \\
\hline \multicolumn{4}{|l|}{ PDR } \\
\hline Early PDR & 2 & 2,5 & \\
\hline High Risk PDR & 6 & 7,5 & \\
\hline Advanced PDR & 12 & 15 & \\
\hline Total & 80 & 100 & \\
\hline \multicolumn{4}{|l|}{ Ocular Rigidity } \\
\hline Low & 4 & 5 & \\
\hline Normal & 71 & 88,8 & $0,0227 \pm 0,0072$ \\
\hline High & 5 & 6,2 & \\
\hline Total & 80 & 100 & \\
\hline \multicolumn{4}{|l|}{$\begin{array}{r}\text { Intraocular } \\
\text { Pressure }\end{array}$} \\
\hline \multicolumn{4}{|l|}{ Normal } \\
\hline Low (10-16 mmHg) & 77 & 96,25 & \\
\hline $\begin{array}{r}\text { Moderate }(16,1-18 \\
\mathrm{mmHg}) \\
\end{array}$ & 3 & 3,75 & $14,475 \pm 1,55$ \\
\hline $\begin{array}{r}\text { High }(18,1-21,9 \\
\mathrm{mmHg})\end{array}$ & 0 & 0 & \\
\hline $\operatorname{High}(\geq 22 \mathrm{mmHg})$ & 0 & 0 & \\
\hline Total & 80 & 100 & \\
\hline \multicolumn{4}{|l|}{ Axial Length } \\
\hline Short $(<23 \mathrm{~mm})$ & 32 & 40 & \\
\hline Normal $(23-25 \mathrm{~mm})$ & 48 & 60 & $23,06 \pm 0,55$ \\
\hline Long $(>25 \mathrm{~mm})$ & 0 & 0 & \\
\hline
\end{tabular}


Table 3. Distribution of Blood Glucose Level and DM Duration

\begin{tabular}{|l|c|c|c|}
\hline & Min & Max & Average \\
\hline Llood Glucose & $\begin{array}{c}80 \\
\mathrm{mg} / \mathrm{dl}\end{array}$ & $\begin{array}{c}528 \\
\mathrm{mg} / \mathrm{dl}\end{array}$ & $259,36 \pm 112,58$ \\
\hline DM Duration & $\begin{array}{c}0 \\
\text { years }\end{array}$ & years & $4,67 \pm 5,28$ \\
\hline
\end{tabular}

The distribution of DR gradation were 6 (7,5\%) mild NPDR eyes, 7 (8,75\%) moderate NPDR, and 7 (8,75\%) severe NPDR eyes. Thirteen (65\%) of NPDR eyes had age for less than or equal 50 years old, and 7 (35\%) of all NPDR eyes either. Two (2,5\%) early PDR, $6(7,5 \%)$ high risk PDR and 12 (15\%) advanced PDR. Eleven (55\%) of PDR eyes had age for less than or equal 50 years old and 9 (45\%) of all PDR eyes either.

Table 4. Distribution of Ocular Rigidity Based On Sample Group (n=80)

\begin{tabular}{|c|c|c|c|c|c|c|c|c|c|c|c|c|}
\hline \multirow{3}{*}{ Group } & \multicolumn{6}{|c|}{ Ocular Rigidity } & \multirow{2}{*}{\multicolumn{2}{|c|}{ Total }} & \multirow{3}{*}{ Median } & \multirow{3}{*}{ Min } & \multirow{3}{*}{$\operatorname{Max}$} & \multirow{3}{*}{$\mathbf{p}^{*}$} \\
\hline & \multicolumn{2}{|c|}{ Low } & \multicolumn{2}{|c|}{ Normal } & \multicolumn{2}{|c|}{ High } & & & & & & \\
\hline & $\mathrm{n}$ & $\%$ & $\mathrm{n}$ & $\%$ & $\mathrm{n}$ & $\%$ & $\mathrm{n}$ & $\%$ & & & & \\
\hline Non DM & 3 & 15 & 17 & 85 & 0 & 0 & 20 & 100 & 0,0182 & 0,0107 & 0,0246 & \\
\hline $\begin{array}{l}\text { DM Non } \\
\text { Retinophaty }\end{array}$ & 1 & 5 & 19 & 95 & 0 & 0 & 20 & 100 & 0,0182 & 0,0107 & 0,0246 & 0,020 \\
\hline NPDR & 0 & 0 & 19 & 95 & 1 & 5 & 20 & 100 & 0,0182 & 0,0107 & 0,0353 & \\
\hline PDR & 0 & 0 & 16 & 80 & 4 & 20 & 20 & 100 & 0,0338 & 0,0181 & 0,0526 & \\
\hline Total & 4 & 5 & 71 & 88,8 & 5 & 6,2 & 80 & 100 & & & & \\
\hline
\end{tabular}

*Chi-Square Test, Significan if $\mathrm{p}=0,05$

The median value ocular rigidity 0,0182 with minimal level 0,0107 and maximal 0,0526. Based on spearman's correlation analysis (table 5), there is a significant (positive) association between sample group and ocular rigidity $(\mathrm{p}<0,05)$.

Table 5. Correlation Between Group Sample with Ocular Rigidity Level

\begin{tabular}{|c|c|c|c|}
\hline CorrelationTest & & $\mathbf{p}^{*}$ & $\mathbf{r}^{€}$ \\
\hline Group Sample & Ocular Rigidity & 0,000 & 0,475 \\
\hline
\end{tabular}

*Spearmen's Rho Correlation, significant if $\mathrm{p}<0,05$ 
The correlation of IOP with sample group are shown in Table 6. There was no difference in IOP between control, diabetic nonretinopathy and degree of retinopathy group $(\mathrm{p}=0,183)$.

Tabel 6. Correlation IOP and Sample Group

\begin{tabular}{|c|c|c|c|c|c|c|c|c|c|c|c|c|}
\hline \multirow{5}{*}{ Group } & \multicolumn{12}{|c|}{$\begin{array}{c}\text { Intraocular Pressure } \\
(\mathrm{mmHg})\end{array}$} \\
\hline & \multicolumn{8}{|c|}{ Level } & \multirow{4}{*}{ Median } & \multirow{4}{*}{ Min } & \multirow{4}{*}{$\operatorname{Max}$} & \multirow{4}{*}{$* \mathbf{p}$} \\
\hline & & & \multirow{2}{*}{\multicolumn{2}{|c|}{$\frac{\text { Normal }}{\text { Moderate }}$}} & \multirow{2}{*}{\multicolumn{2}{|c|}{ High }} & \multirow{2}{*}{\multicolumn{2}{|c|}{ High }} & & & & \\
\hline & \multicolumn{2}{|c|}{ Low } & & & & & & & & & & \\
\hline & $\mathrm{n}$ & $\%$ & $\mathrm{n}$ & $\%$ & $\mathrm{~N}$ & $\%$ & $\mathrm{n}$ & $\%$ & & & & \\
\hline Non DM & 18 & 90 & 2 & 10 & 0 & 0 & 0 & 0 & 14,5 & 12 & 18 & 0,183 \\
\hline $\begin{array}{l}\text { DM Non } \\
\text { Retinopathy }\end{array}$ & 19 & 95 & 1 & 5 & 0 & 0 & 0 & 0 & 15 & 12 & 17 & \\
\hline NPDR & 20 & 100 & 0 & 0 & 0 & 0 & 0 & 0 & 15 & 12 & 16 & \\
\hline PDR & 20 & 100 & 0 & 0 & 0 & 0 & 0 & 0 & 14 & 12 & 16 & \\
\hline
\end{tabular}

\section{Discussion}

Diabetic retinopathy is the disorder of microvascular in the retina. So it is the leading cause of blindness. A correlation exists between diabetic retinopathy and increased risk of life threatening vascular complication like coronary artery disease. The stages of diabetic retinopathy categorized as; non-proliferative diabetic retinopathy to proliferative diabetic retinopathy. The signs of non-proliferative in retina dot blot hemorrhages, microaneurysms, hard exudates and cotton wool spots. The proliferative diabetic retinopathy is retinal neovascularization. ${ }^{1}$ Ocular considered to be primary cause influencing change in ocular stiffness. ${ }^{4}$

In this study, we detected a statistically significant difference ocular rigidity (OR) value between diabetic patients and controls. A positive correlation and clear trend for higher OR was documented in patients with PDR 4 (20\%) and NPDR 1 (5\%) compared other group sample $(\mathrm{r}=0,475, \mathrm{p}=0,000)$. The finding of Sahin et al showing that diabetes affects corneal biomechanics and results in lower corneal hysteresis values than those in healthy control subjects, are in accordance with this hypothesis. ${ }^{5}$ In addition, increased AGE accumulation distributed around blood vessels has been found in the retinal vessels of diabetics, increasing with the severity of retinopathy. Based on the common background of AGE accumulation in 
retinal perivascular space and sclera that possible changes in OR in diabetes may evolve in parallel with diabetic retinopathy. 6,7

Eighty eye sample were studied. Fourty sample were diagnosed with diabetic retinopathy, 20 without diabetic retinopathy and 20 control group. There was no significant difference between the mean IOP of patients with diabetic retinopathy and without diabetic retinopathy. Also there was no significant difference between the diabetic retinopathy grades ( $p$ value $=0,183$ ). Mehdi Moeni et al (2016) reported that there was no a significant correlation between IOP and grade of diabetic retinopathy ( $\mathrm{p}$ value $=0,07) .{ }^{3}$ Kenji sakata et al (2000) also reported that not significant correlation of IOP result between diabetic patients without retinopathy $(\mathrm{p}=0,113)$ and diabetic patients with retinopathy $(\mathrm{p}=0,474) .{ }^{8}$ Masato Matsuoka et al (2012) reported that IOP was significantly correlated with HbA1c in patients with diabetic retinopathy although the stage of diabetic of diabetic retinopathy was not associated with IOP. High glucose in the blood or some aspects of glucose metabolism could affect IOP. ${ }^{9}$ Diabetes mellitus is known to cause microvaskular damage and may affect the autoregulatory action of the blood vessels in the retina and optic nerve. Diabetes has been found to be associated with elevated IOP and has therefore been suggested to be a possible risk factor for glaucoma, particulary open-angle glaucoma. However, the evidence to support this relationship remains inconsistent. The mechanism that cause higher IOP in diabetic patients were not determined. Suggested that genetic factors, dysfunction of the autonomic system in diabetic patients might contribute to increased IOP, elevated blood glucose level induces an osmotic gradient with consequent fluid shifts into the intraocular space which elevated IOP. ${ }^{4,10}$

Based on Spearman test analysis was not significant correlation between axial length, IOP and ocular rigidity. Chinawa et al (2017) reported that not significant correlation between IOP and axial length. Considering the impact of IOP on myopic status a study showed that higher IOP might result in greater scleral stress and faster axial elongation translating to greater myopic progression. Friedman has also proposed a mathematical model that suggest the myopic eye is under greater stress than an emmetropic eye with the same IOP. This agrees with our study where there was poor correlation between IOP and axial length. ${ }^{11}$

There was a significant correlation between ocular rigidity and IOP in the group without DM $(r=0,669, p=0,001)$, NPDR and PDR $(r=0,865, p=0,000)$. However, in the analysis of the DM group without retinopathy there was no significant relationship between ocular rigidity and IOP $(r=0,260, p=0,268)$. There is a significant correlation between ocular rigidity and 
intraocular pressure in people with type 2 diabetes mellitus. Kurita et al (2008) reported based on mathematical theory and exsperimen was found that linier relationship between ocular rigidity and IOP. ${ }^{12}$ Ocular rigidity is a macroscopic parameter characterizing the relationship between pressure and volume changes in the human eye. Ocular rigidity depends on the architecture and material properties of the globe. The theories relating material properties and geometry of the optic nerve and scleral wall and the resulting level of IOP related stress and strain with the pathogenesis and progression of glaucomatous optic neuropathy and susceptibility to damage. Although the stiffness of the sclera has been proposed as a major determinant of optic nerve head biomechanics, it is also the interaction between geometry and mechanical factors that is suggested to influence IOP related stress and strain. Ocular rigidity coefficient in living and dead rabbit eyes that had been subjected to raised IOP has been reported. ${ }^{2}$

In our study, the mean ocular rigidity value for males was 0,0216 (range 0,0107 0,0349) and females was 0,0220 (range 0,0107-0,0526). Females appear to have a higher ocular rigidity than males. However, the gender effect and ocular rigidity correlation was not statiscally significant ( $p>0,05)$. These results were close to a study performed by Elena Wong et al (1991), which obtained mean ocular rigidity for male 0,0143 (SD $\pm 0,0051)$ and female $0,0168$ ( $\mathrm{SD} \pm 0,0064)$. This studied was recorded higher ocular rigidities for females than males although the difference in those studies were not statistically significant. The influence of the menstrual cycle on ocular rigidity has been studied and no significant effect was found. It is likely that the steeper corneas and shorter axial lengths (and therefore smaller ocular volume) in female contribute to a higher ocular rigidity. ${ }^{13}$

A statistically significant positive correlation between ocular rigidity and age of the patients was found based on post hoc analysis $(\mathrm{p}=0,026)$. The mean value of age with normal ocular rigidity was 47,93 ( $\mathrm{SD} \pm 4,04)$ years old and $52(\mathrm{SD} \pm 3,60)$ years old with high ocular rigidity. Pallikaris et al (2005) reported that a statistically significant positive correlation between the rigidity coefficient and age was found $(\mathrm{p}=0,02) .{ }^{2}$ Baptiste et al (2015) reported that older age was associated with a lower degree of fiber alignment and larger matrix stiffnes for both diabetic and non-diabetic scleras. The age related increase in matrix stiffness was $87 \%$ larger in diabetic specimen compared to non diabetic controls and diabetic scleras had a significantly larger matrix stiffness $(\mathrm{p}=0,01)$. This study suggests that the age-related increase in scleral stiffnes is accelerated in eyes with diabetes, which may have important implication 


\section{semwaxnan JOURNAL OFOPHTHALMOLOGY}

ध50

in glaucoma. An increase in the ocular rigidity coefficient with increasing age was first reported by Friedenwald in a large series of human eyes. An increase in stiffness and decrease in thickness of the peripapillary and posterior sclera with age has also been reported in primates, while measurement in human scleral segments also indicate a relationship between age and elasticity of the sclera. Although it is difficult to draw a definitive conclusion about the association between age and ocular rigidity, the following offers a possible biological explanation for this association. It has been shown that the number of cross-links between collagen fibers caused by glycation increases with increasing age. ${ }^{14}$

There was significant correlation between age and IOP $(\mathrm{p}=0,013)$. IOP has been reported to be higher in older eyes. Qureshi (1995) reported that as age increases, intraocular pressure also increases, with an average of $0,28 \mathrm{mmHg}$ per decade. IOP increases progressively with age until 60 years. When the mean IOP of one age group was compared with its preceding age group, the increase is statistically non- significant until the age of 40 years and highly significant $(p<0,001)$ in the age groups 41-50 and 51-60 years. 15 The mean IOP increases after the age of 40 years, possibly due to reduced facility of aqueous outflow. Histologic studies indicate a number Histologic studies indicate a number of age-related changes in the trabecular meshwork, including thickening and fusion of the trabecular sheets, degeneration of collagen and elastic fibrils, accumulation of wide-spacing collagen, loss of endothelial cells, hyperpigmentation of the endothelial cells, accumulation of intracellular organelles, accumulation and alteration of extracellular matrix and decrease in the number of giant vacuoles. $^{16-18}$

The data were analysed to establish whether there was not significant relationship between DM duration and ocular rigidity ( $\mathrm{p}$ value=0,05). Panagiotoglou et al (2015) was reported that diabetic patients exhibit a trend for higher ocular rigidity values as the severity of diabetic retinopathy worsens, although the difference did not reach statisticaly significance difference in ocular rigidity and outflow facility between diabetic patients and normal controls.1 Stratton et al (2001) found that development of retinopathy (incidence) was strongly associated with baseline glycaemia, glycaemic exposure over 6 years, higher blood pressure and with not smoking.19 The long duration of DM can influence of diabetic retinopathy severity. The long duration of hyperglycaemia exposure will cause celluler changes from retina membrane basalis, loss of pericyte cell and endothel disfunction.20 In this study we were not able to document any significant difference in DM duration and ocular rigidity. Significant 
limitation of our work include the relatively small number of patients enrolled ( 80 sample) and sample with DM duration over than 6 years is 24 sample (30\%).

There was no significant correlation between DM duration and IOP in group sample (p>0,05). Vladimir et al (2017) also reported that there was not significant difference in IOP and DM duration.21 Meanwhile, Kanishk et al (2017) reported that the intraocular pressure values were higher in the subject with diabetes in all the age groups. 22 The study also revealed that the mean IOP was higher in diabetic patients with more than 5 years of duration. These differences could probably due to different size of sample, population characteristics, and DM duration of the study.

Multiple linier regression analysis showed that the ocular rigidity was significantly associated IOP and diabetic retinopathy grades. Similar with study by Masako shirane et al (2012) found that ocular stiffness was found to be proportional to the product of IOP and radius of curvature of the cornea, the other factors were not significantly associated with ocular stiffness. For an individual eye, because the value of the radius of corneal curvature was unchanged, ocular stiffnes was proportional to IOP. Among many factors presumed to affect ocular stiffness, true IOP is the only factor that changes over a short period. Thus, the change in true IOP is considered to be primary cause influencing change in ocular stiffness.23 Based on the common background of AGE accumulation in retinal perivascular space and sclera possible changes in ocular rigidity in diabetes may evolve in parallel with diabetic retinopathy.1,5,14 Multiple regression analyses showed the IOP was associated with ocular rigidity, age, blood glucose level, axial length dan duration of DM. Barbara et al (1991) was reported that mean IOP was increased significant with age. There was difference IOP and gender but not significant.24 Anna et al (2009) found that there was a nonlinear pressure volume relation in the living human eye characterized by an increase in rigidity at higher IOP levels.25 Anselm Hennis et al (2003) found that baseline diabetes history and hypertension, as well as older age, elevated GHb, higher blood pressure and lower baseline IOP were associated with a 4 year increase of IOP. ${ }^{26}$

\section{Conclusion}

In conclusion, our finding showed that there was a significant correlation between ocular rigidity with intraocular pressure in people with type 2 diabetes mellitus. Diabetic patients exhibit a trend for higher ocular rigidity values as the severity of diabetic retinopathy worse. Patients with diabetes require regular follow up to optimize their glycemic and 
intraocular pressure to prevent development and progression of diabetic retinopathy and other diabetes-related complications.

\section{References}

1. Panagiotoglou, Theonitsa, et al. Clinical Study: Ocular Rigidity and Outflow Facility in Nonproliferative Diabetic Retinopathy. Hindawi Publishing Corporation Journal of Diabetes Research Volume 2015, Article ID 141598, 6 Pages

2. Pallikaris, Ioannis, et al. Ocular Rigidity. Expert Review of Ophthalmology. 2010;5(3): $343-351$.

3. Moeini, Mehdi, et al. The Intraocular Pressure of Type 2 Diabetic Patients Comparison in Diabetic Retinopathy Grades. Iranian Journal of Diabetes and Obesity, Volume 8, Number 3, 2017; 151- 156.

4. Guilherme, luis, et al. Association between Glucose Levels and Intraocular Pressure: Pre and Postprandial Analysis in Diabetic and Nondiabetic Patients. Hindawi Publishing Corporation. Journal of Ophthalmology. Volume 2015, Article ID 832058, 5 pages.

5. A. Sahin, et al., Corneal Biomechanical Changes in Diabetes Mellitus and Their Influence on Intraocular Pressure Measurements, Investigative Ophthalmology and Visual Science, vol. 50, no. 10, pp. 4597-4604, 2009.

6. M. Chen, T. M. Curtis, and A. W. Stitt, "Advanced Glycation End Products and Diabetic Retinopathy," Current Medicinal Chemistry, vol. 20, no. 26, pp. 3234-3240, 2013.

7. A.W. Stitt, "The Role of Advanced Glycation in The Pathogenesis of Diabetic Retinopathy,” Experimental and Molecular Pathology, vol. 75, no. 1, pp. 95-108, 2003.

8. Sakata, Kenji, et al. Analysis of The Intraocular Pressure in Diabetic, Hypertensive and Normal Patients (Glaucoma Project). ARQ. BRAS. OFTAL. 63(3), JUNHO/2000, 223-226.

9. Matsuoka, Masato, et al. Intraocular Pressure in Japanese Diabetic Patients. Dove Medical Press Ltd. Clinical Ophthalmology 2012:6 1005-1009.

10. Mitchell, Paul, et al. Open Angle Glaucoma and Diabetes. The Blue Mountains Eye Study, Australia. Ophthalmology 1997; 104:712-718. 
11. Chinawa, et al. Is There A Causal Relationship between Myopia and Intraocular Pressure. British Journal of Medicine \& Medical Research, 20(10): 1 - 7, 2017; Article no. BJMMR. 30241.

12. Y. Kurita, et al. Contact-based Stiffness Sensing of Human Eye. IEEE Trans. Biomed Eng. 55: 739-745, 2008.

13. Wong, Elena, Maurice Yap. Factor Affecting Ocular Rigidity in The Chinese. Clinical \& Experimental Optometry; 74.5; 1991 September/October; 156-159.

14. Coudrilier, Baptiste, et al. Effects of Age and Diabetes on Scleral Stiffness. Journal of Biomechanical Engineering. July 2015, Vol 37/ 071007(1-8).

15. Qureshi, IA. Age and Intraocular Pressure: How Are They Correlated? Journal Of Pakistan Medical Association 45:150,1995; 150-152.

16. Stamper, L Robert, Marc F Lieberman, Michael V Drake. Becker-Shaffer's. Diagnosis and Theraphy of The Glaucomas. Chapter 1. Mosby. Elsevier. 2009.

17. Khurana AK. Comprehensive Ophthalmology. Fourth Edition. New Age International (P) Limited. New Delhi: 2007.

18. Vaughan Daniel G, MD; Asbury Taylor, MD; Riordan Evan Paul, FRCS, Frcophth; Oftalmologi Umum, Widya Medika, Jakarta 2000.

19. Stratton, I., Kohner, E., Aldington, S. et al. Risk Factor for Incidence and Progression of Retinopathy in Type II Diabetes. Diabetologia (2001) 44(2):156-63.

20. Sesanti. 2008. Hubungan Lama Menderita Diabetes dengan Derajat Retinopati Diabetik Pada Pasien Diabetes Mellitus TIpe II di RSU Haji Surabaya JanuariDesember 2008. Medical Jurnal 2010.

21. Canadanovic, Vladimir, et.al. Incidence of Diabetic Eye Disease in Accordance with Duration, Glycemic Control, Blood and Ocular Pressure. Med Pregl 2017; LXX (1112): 353-358).

22. Singh, Kanishk, et.al. Effect of Type II Diabetes Mellitus on Intraocular Pressure in Central India. Indian Journal of Clinical and Experimental Ophthalmology. JanuaryMarch. 2017;3(1): 28-30.

23. Shirane, Masako, et.al. Influence of Ocular Stiffness on Intraocular Pressure Estimation Using Goldmann Applanation Tonometry. Journal of Medical and 


\section{SRIWIJAYA JOURNALOFOPHTHALMOLOGY}

ध्रु०

Biological Engineering. 33(3): 293-300.

24. Klein, Barbara, et al. Intraocular Pressure in An American Community. The Beaver Dam Eye Study. Investigative Ophthalmology \& Visual Science, Vol. 33:2224-2228, No. 7, June 1992.

25. Dastiridou, Anna I, et al. Ocular Rigidity, Ocular Pulse Amplitude, and Pulsatile Ocular Blood Flow: The Effect of Intraocular Pressure. Investigative Ophthalmology \& Visual Science, December 2009, Vol. 50, No. 12. Page 5718- 5722

26. Hennis, Anselm, et al. Hypertension, Diabetes and Longitudinal Changes in Intraocular Pressure. American Academy of Ophthalmology. 2003;110:908-914. 
